Nuclear Regulatory Commission

More licence for nuclear industry?

Washington

CITING the increased maturity of the nuclear industry, the Reagan Administration has begun to urge Congress to streamline the procedures used by the Nuclear Regulatory Commission (NRC) to license new power plants. A Department of Energy (DOE) bill, the subject of heated Senate hearings, proposes condensing the present two-step licensing procedure into a single stage, curbing the number and scope of public hearings and limiting the ability of NRC to impose new safety requirements once construction of a plant is under way.

In hearings last week, Ellyn Weiss, representing the Union of Concerned Scientists, said it was "unconscionable" for Congress to reduce public oversight of nuclear safety and draw the already blunted teeth of NRC. The most controversial ingredient of the DOE bill is a provision to limit the authority of NRC to insist on design changes once it has licensed the construction of a plant. The industry blames the proliferation of design changes - known as "backfitting" - for many of the delays and cost overruns experienced by nuclear power plants. Under the new bill, NRC would be allowed to impose a backfit only if it could prove that the change would "substantailly" enhance overall safety and that the extra cost could be justified. In addition, all backfitting would have to be approved in person by the NRC commissioners - a proposal the commission itself claims will result in serious administrative bottlenecks.

A second major change would do away with the separate hearings conducted by NRC at the building permit and operating licence stage of power plant construction. Permission to operate a new plant would be granted at the same time as permission to build, subject only to later "certification" - by the utility itself - that the plant had been built in accordance with the original plans and would operate safely. Public hearings would be held only at the original licensing stage and would no longer be "adjudicatory", with sworn testimony and the cross-examination of witnesses.

Energy Secretary Donald Hodel, explaining the new procedure, told the committee that by combining the operating licence and building permit, NRC would be able to make public participation more " "meaningful", as well as reassure contractors that they would not be prevented from operating power plants that had been built at enormous cost. To qualify for the joint permit, he maintained, contractors would have to provide NRC with more complete design plans early in the licensing procedure, giving critics of the plant "a real target at which to shoot".

Critics of the bill have ridiculed the administration's contention that the changes would increase opportunities for public participation. In her Senate testimony, Ms Weiss noted that there would no longer be automatic public hearings after a plant had been built and before it was turned on. More significantly, she said, a change in the legal character of any hearings - from an adjudicatory to a "hybrid" hearing - would place "outlandish and onerous" obstacles in the path of members of the public who wanted to intervene at any stage of the licensing procedure.

Under hybrid hearings, intervenors would no longer be permitted to call and cross-examine witnesses unless they could first prove to the commission that there existed "genuine and substantial disputes of fact which can be resolved with sufficient accuracy only by introduction of evidence at a formal hearing"'. But they would not be allowed, before proving that such disputes of fact existed, to question utility experts or NRC staff. Such a change, Ms Weiss claimed, would result in wasteful litigation to establish whether a disputed accurately resolved.

The Union of Concerned Scientists has also vehemently opposed the proposal to limit the scope of backfits ordered by NRC. Weiss told the committee that most examples of backfitting did not result from changes in NRC regulation but from the belated discovery of deficiencies in plant design. NRC Commissioner Victor Gilinsky, in earlier testimony, said that NRC regulations had become more detailed and prescriptive only because of the "uneven" safety performance of the nuclear utilities and their inability to regulate themselves.

Although the administration's bill has received enthusiastic support from the industry, NRC has produced an alternative bill which offers some streamlining of procedures but retains more licensing hurdles and safeguards. It would leave the scope of backfitting to the commission to resolve administratively, and it would retain the right of members of the public to call for a hearing after a plant had been built. Like the DOE bill, the NRC legislation would combine the operating licence and construction permit, but an NRC review of a completed plant would be required before it could start operation.

Dissenting from his NRC colleagues, commissioner Gilinsky said he could not understand how the single-stage licensing procedure could be coupled with a compulsory review of a power plant after it had been built. "So long as the law tells a utility building a plant that it has a licence, and at the same time tells the regulators that it is still up to them to determine the readiness of the plant for operation, someone is being fooled", he said.

Peter David fact was "substantial" or could be
UK overseas development

"fayner's cuts

BRITISH Government plans to scale down the work of four scientific units run by the Overseas Development Administration (ODA) are criticized in scathing terms in a House of Commons Select Committee report published last week. Concluding that the severe staff and budget cuts intended for the four units are based on scrutinies that are "fundamentally flawed", the committee asks the government to suspend its decisions and think again.

The report was compiled by a subcommittee of the Foreign Affairs Committee (FAC) chaired by Labour MP Frank Hooley. The ODA scientific units, which carry out training and research into problems of developing countries, have in the past two years been scrutinized by Lord Rayner, formerly the Prime Minister's advisor on Whitehall efficiency. As a result, scheduled staff levels have already been cut to 75 per cent of the 1979 total, with further reductions planned. And two of the units have been amalgamated. FAC says the Rayner scrutinies were concerned only with costs, rather than efficiency, and that the total cost of the units ( $£ 14.3$ million this year) is "minute" in relation to their value to developing countries.

One of the units, the Centre for Overseas Pest Research, has already been forced by cuts to abandon its trials of the mollusc icide, nicotinanilide, against the snail vector of schistosomiasis just as "success was imminent". This year the centre was

\section{New men at ministry}

Prime Minister Margaret Thatcher's postelection reshuffle, to the surprise of many, left Sir Keith Joseph still in charge at the Department of Education and Science. Two new under secretaries have been appointed, however, Mr Peter Brooke (left) and Mr Robert Dunn. The division of

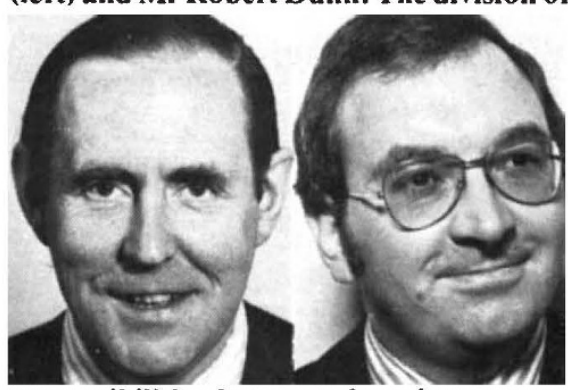

responsibilities between them has not yet been announced, but it is likely that $\mathrm{Mr}$ Brooke will take over from William Waldegrave (now at the Department of the Environment) in (he department's dealings with the University Grants Committee. Mr Brooke, aged 49, a graduate of Balliol College Oxford and the Harvard Business School, was vice president of the National Union of Students in 1955-56. 
formally united with the Tropical Products Institute, which specializes in post-harvest storage, to form the Tropical Development and Research Institute. The new institute, which is still seeking a site, is planned to save $£ 475,000$ through a "greater concentration of effort" and staff reductions of 10 per cent. FAC says the merger was not warranted by the Rayner scrutinies, which took "no serious account" of the value of training and scientific information the units provide. It says funds for the two units were well spent and that resources for both should be increased. The merger is widely unpopular with staff of the new institute.

Of the other two units, the Directorate of Overseas Surveys, which produces specialist maps and surveys, will cease to exist in its present form and will be merged with the Ordnance Survey. The government's scrutiny by the Rayner Unit found the directorate to be inclined to an "overartistic" approach to cartography but recognized it as a centre of excellence. The move to Ordnance Survey's headquarters at Southampton will involve staff reductions of 60 per cent, and many cartographers have already resigned. FAC concludes, after consultations with international aid organizations, that the need for surveying and mapping in developing countries is increasing and doubts whether the directorate will be able to sustain its "highly regarded" work if the planned changes are made.

The Land Resources Development Centre (formally a "special" rather than a "scientific" unit) is to have its staff complement cut to 45 , from a 1979 figure of 83. FAC says that the reduction will decrease the centre's cost-effectiveness, which it says compares well with the private sector. The centre is concerned with applied land-use research and undertakes training in developing countries.

The government's plans for the four units, which account for 1 per cent of the overall aid budget, are described by FAC as "a short-sighted error for the sake of small and short-term savings"; the damage to the units, which have an "extremely high international reputation", will "probably be irreversible".

FAC endorses the government's aims of increasing efficiency and encouraging the units to act in a more entrepreneurial manner; this would, it says, increase flexibility as well as efficiency. The aims are consistent with the general enthusiasm in government for "privatization" and the Rothschild customer/contractor principle. But FAC says the units must have more reliable central funding and should be permitted to seek additional funds from outside sources if their accumulated expertise is to be protected. It is not known how the government will respond to the FAC report; however, one senior ODA official, asked what impact the report may have, said "Almost certainly none at all".

Tim Beardsley

Soviet oceanography

\section{Costly neglect of plate tectonics}

SOVIET neglect of plate tectonics could have serious economic consequences, two leading Soviet oceanologists warned recently. In a major article in Pravda, Dr Andrei Monin, director of the Institute of Oceanology of the Soviet Academy of Sciences and Dr Leonid Brekhovskikh, secretary of the Academy's Department of Oceanology, Atmosphere Physics and Geography, accused the Ministry of Geology of making insufficient use of recent advances in tectonics. Moreover, they said, the Ministry of Higher and Specialized Secondary Education needed to update university courses in geology, which dealt only superficially with tectonics.

By the time the article had appeared in Pravda, Dr Brekhovskikh was aboard the research ship Academik Mstyslav Keldysh, leading a major expedition with an acoustic monitoring programme aimed at developing rapid acoustic methods for the location of iron and manganese nodules on the seabed. So far, sea-bed exploration has been left almost entirely to the initiative of the Academy of Science's "Commission on Problems of the World Ocean" - which coordinates the efforts of the Institute of Oceanology, the four earth-sciences institutes, and also the Far Eastern Centre of the Soviet Academy and the Institute of Geological Sciences of the Ukrainian Academy. But the main initiative in undersea exploration has come from the oceanologists - largely due to the reluctance of certain leading geologists, notably $\mathrm{Dr}$ Vladimir Belousov, to accept the theory of plate tectonics. This divergence of opinion was carefully glossed over by Monin and Brekhovskikh with a call for "greater creative cooperation" between oceanologists and geologists, and an allusion to the work done by Soviet oceanologists in the development of plate tectonics.

During the past decade, Soviet oceanologists have, indeed, made a number of notable advances, including the 1976 expedition of the Dmitrii Mendeleev, which yielded unique rock specimens from layers 2 and 3 of the oceanic crust, the magnetic survey of the Baltic by the vessel Zarya in 1981 and the tectonic mapping of ore occurrence and recovery of iron-manganese nodules in the neighbourhood of the Owen fracture by the Akademik Vernadskii in 1979. Very little such work, however, has been organized from the geologists' side one notable exception being the Bellinghausen and Gidrolog expedition of 1979 , which was a joint venture of the Institute of Geology of the Ukrainian SSR and the naval hydrographic service.

The use of submersible manned and remote-controlled craft has played a major role in these ventures. These are generally multipurpose vehicles, which combine the recovery of bed samples with the photography and video-recording of marine life. They include the Argus, which can operate at depths of $600 \mathrm{~m}$ and glides over the bottom on ski-supports, and the Pisces, which can operate to depths of $2,000 \mathrm{~m}$, the Manty and $K r a b$, which are equipped with special manipulators, and the Okeanolog, which has electrohydraulic grabs capable of removing up to $20 \mathrm{~kg}$ of bed samples at a time, and fitted with special engines enabling it to "hover". However, although the Soviet Union can boast of more than 120 research ships (not counting almost the same number of specialized vessels of the hydrometeorological and fisheries services) it has fallen badly behind as regards research submersibles. In all, say Monin and Brekhovskikh, there are some 200 such craft in the world - but only "twentyplus" of these belong to the Soviet Union. The "further development of earth sciences and the needs of [Soviet] industry" they conclude, requires the considerable expansion of the submersible "fleet" in the nearest future. Vera Rich

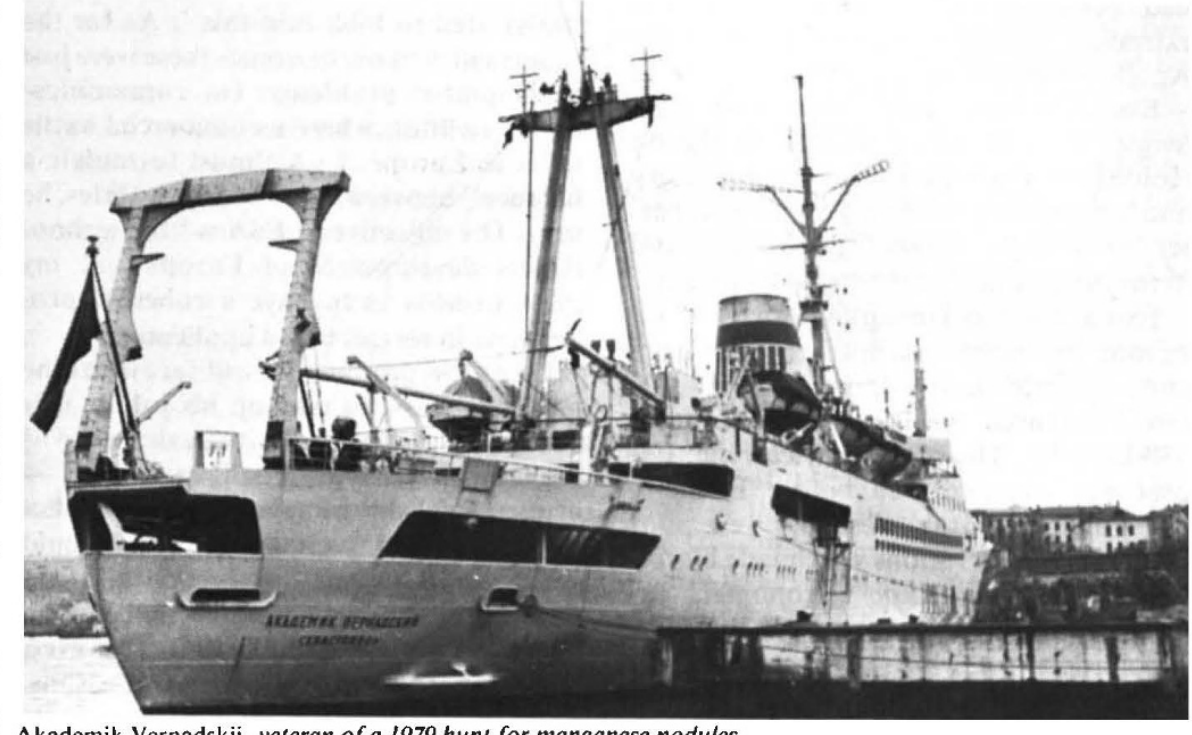

Akademik Vernadskii, veteran of a 1979 hunı for manganese nodules 